\title{
The Hungerford Disaster A Late Perspective of the Military Experience
}

\author{
Flight Lieutenant A J Forester \\ FRCS (Ed), RAF, Registrar in General Surgery
}

\author{
Major C A Pailthorpe \\ FRCS (Ed), RAMC, Senior Registrar in Orthopaedic Surgery
}

\author{
Lt Col J M Ryan \\ FRCS, RAMC, Senior Lecturer in Military Surgery \\ The Surgical Unit, Princess Alexandra Hospital, RAF Wroughton, Swindon, Wiltshire SN40QY
}

\begin{abstract}
SUMMARY: Two years have passed since the worst firearms incident in recent British civil history. Most of the casualtie were managed at a local district general hospital; this experience was reported soon afterwards ${ }^{1}$. Two casualties wer $\omega^{\omega}$ managed at Princess Alexandra's Hospital, RAF Wroughton; both are still under review. This paper describes their injuries, investigations and treatment. Current thoughts on optimal management are discussed; areas of particular controversy are highlighted.
\end{abstract}

\section{Introduction}

In August 1987 a young adult male ran amok in the Berkshire town of Hungerford, creating the worst firearms incident in recent British civil history. The police estimate 119 rounds were fired from three weapons. Thirty casualties resulted; fourteen died before definitive (hospital) treatment. Fourteen casualties were admitted to the Princess Margaret Hospital, Swindon; two died later due to major vascular injury ${ }^{1}$. One casualty with serious head wounds died following transfer to a neurological centre. Two casualties were admitted to the Princess Alexandra Hospital, RAF Wroughton where emergency surgery was carried out.

\section{Case 1}

A 20 year old male was wounded in the right arm by a $9 \mathrm{~mm}$ pistol bullet from an estimated range of 15 metres. Injury had occurred $6 / 7$ hours before. Aggressive resuscitation with Haemaccel had been instituted by an on-site medical team; opiate analgesia was also given ${ }^{2}$. As a result of this effective initial management the patient arrived in a stable and alert condition. The history given suggested that the missile had richocheted off a windscreen pillar and entered the victim's right forearm. An entry wound, $1.5 \mathrm{~cm}$ diameter, was noted on the flexor aspect $3 \mathrm{~cm}$ proximal to the thenar eminence; there was no exit wound. Neurological assessment revealed sensory impairment in the distribution of the anterior cutaneous branch of the median nerve. Radiographs revealed a deformed missile lying close to but not involving the radius at mid forearm level (Fig 1). There was marked contusion of the overlying skin, a feature known to be associated with deformation of a bullet at impact.

Benzyl penicillin and tetanus toxoid were given in accordance with antibiotic Casualty Treatment Regimes
(CTRs). The wound was explored in orthodox militarn surgical fashion by wide incision of skin in the long axio of the forearm; skin excision was kept to a minimum ${ }^{3}$ 을 Wound debridement was achieved by incising the degre fascia along the length of the skin incision, an essenడై prerequisite to proper exploration and wound excisi Injury to muscle was minimal; an expected finding uit. a short wound track with involvement of soft tissue orky A small amount of muscle considered non-viable fas excised with scissors. The criteria of colour, consister contractility and capillary bleeding were used as guide to the extent of the muscle excision ${ }^{4.5}$. The deforn bullet was easily located and removed. There was no visible evidence of major neural or vascular injuryळ Following wound excision the wound was irrigated witt hydrogen peroxide, the wound cavity was dressed witlo fluffed gauze, multiple layers of dressing gauze, woot and crepe. All wound layers, including the fasciotomy were left open, a mandatory step in missile woun management. At 5 days, the wound was inspected i theatre under general anaesthesia; partial delaye primary closure was undertaken, leaving a small defect which was later closed by application of a split skin graft

Recovery was uneventful and the soft tissues heale uneventfully. At a recent assessment, a continuing sensory impairment involving the anterior cutaneous. branch of the median nerve was still cvident.

\section{Case 2}

A 68 year old woman received a wound caused by $7.62 \mathrm{~mm}$ bullet fired from an assault rifle; estimate range was 30 metres. She was found by a medical teanN about three hours after injury. She had bled copiously. was shocked and in severe pain. An intravenous infusio of Haemaccel was commenced and an opiate analgesi $\mathbb{\omega}_{\mathbf{\omega}}$ administered $^{2}$. Examination revealed an elderly ladg 


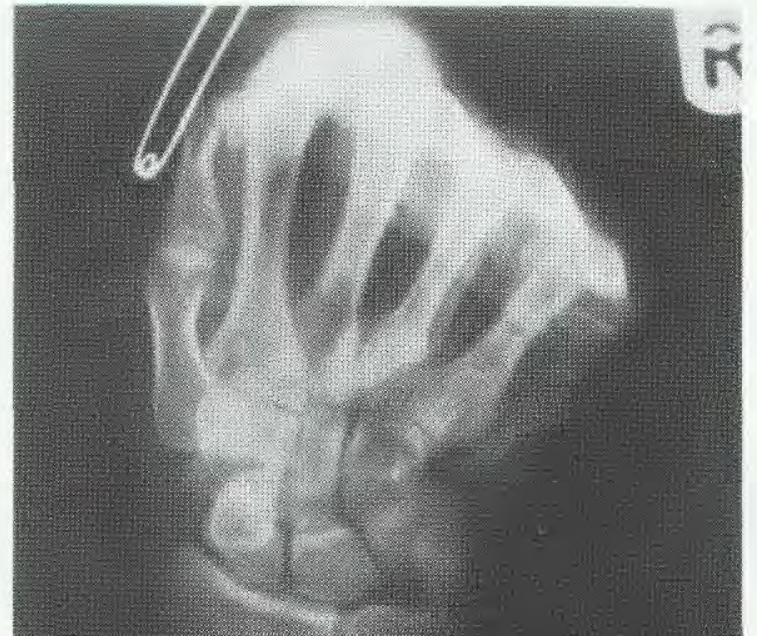

who had been very effectively resuscitated. A $1 \mathrm{~cm}$ entry wound was found in the left groin; a larger and more ragged exit wound $(1.5 \mathrm{~cm})$ was noted overlying the left buttock. Considerable contusion, extending over $10 \mathrm{~cm}$, surrounded the exit wound, a feature of this type of injury and reported previously by Fackler and his colleagues ${ }^{\circ}$. A complete foot drop was noted and there was sensory loss along the lateral aspect of the calf extending onto the dorsum of the foot. There was no clinical evidence of vascular impairment and all pedal pulses were present. X-ray examination revealed disruption of the left femoral head and injury to the acetabulum (Fig 2).

Following the administration of benzyl penicillin and tetanus toxoid, wound exploration was undertaken under general anaesthesia. The exit wound was approached first; skin was incised towards the greater trochanter revealing a large cavity in the soft tissues

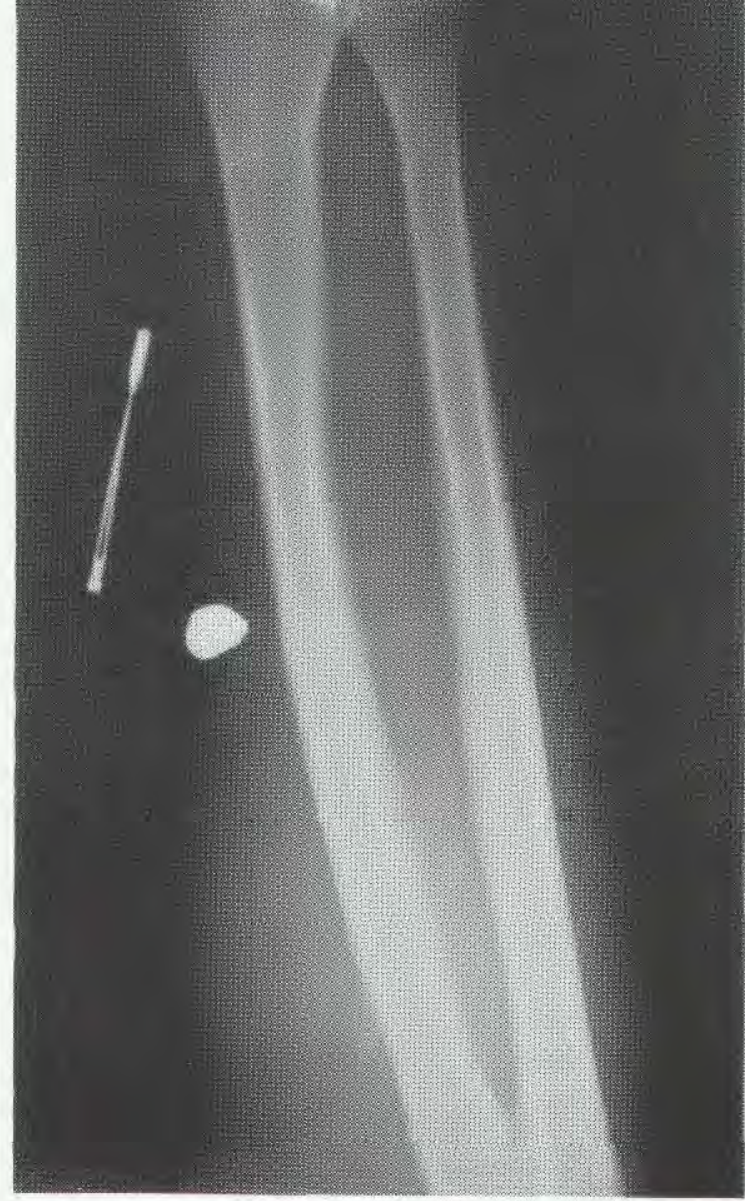

Fig 1. Case No 1. A deformed missile lies close to the radius.

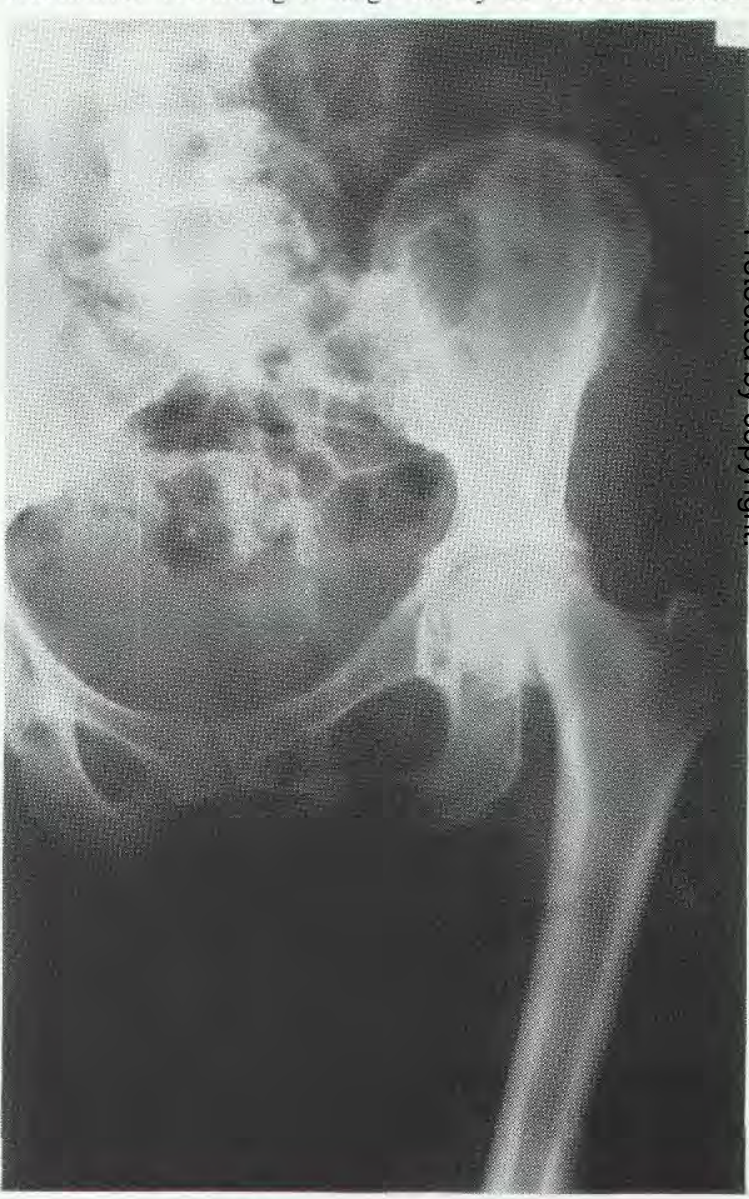

Fig 2. Case No 2. Disruption of the left femoral head and acetabulum. 
which extended into the pelvis. The cavity was filled with lacerated, non-viable muscle and bone fragments, features compatible with high energy-transfer. Injury to muscle involved the gluteii, gamelli, obturators and quadratus femoris. The sacrum was exposed with destruction of the sacrotuberous and sacrospinous ligaments. The sciatic nerve was transected across two thirds of its width on the lateral side. Almost complete disintegration of the femoral head was confirmed and the posterior wall of the acetabulum was disrupted.

The missile had effectively debrided the wound and there was evidence that a considerable amount of soft tissue had been ejected, a feature of perforating high velocity assault rifle bullet wounds reported by Fackler et $\mathrm{al}^{6}$. Wound excision proceeded, removing all nonviable muscle and small unattached bone fragments. The entry wound was then explored by skin incision laterally, keeping skin excision to a minimum. The full extent of the missile track was now evident; it was noted to pass retroperitoneally and lateral to an intact femoral nerve. Muscle injury involving rectus femoris and disruption to the anterior lip of the acetabulum was noted. Wound excision proceeded in orthodox fashion. On completion, the track and cavity were irrigated with hydrogen peroxide. The wounds were dressed as described for Case 1. A Denham pin was inserted through the upper tibia to facilitate the maintenance of postoperative balanced traction. Delayed primary closure (DPS) was achieved at 5 days; closure was preceeded by irrigation with a solution of gentamycin in normal saline, a step taken in view of extensive bone and joint involvement.

Soft and bony tissues healed uneventfully. The foot drop and sensory loss persist and a lively splint is in use. The degree of femoral head and acetabular destruction grossly limited ambulation in the months following injury and a total hip arthroplasty has just been performed.

\section{Discussion}

Both patients arrived in stable condition as a result of effective resuscitation carried out at the scene by primary care teams. These dramatic resuscitative efforts were carried out at considerable risk to the personal safety of these teams.

Our patients presented to a military hospital with ballistic injuries typical of those encountered on the battlefield and were managed in standard military surgical fashion. This orthodox approach, described fully by Kirby and Blackburn ${ }^{3}$, remains mandatory in all British Military Hospitals. This is in spite of an increasing trend towards surgical conservatism in civilian hospitals, particularly in the United States ${ }^{6,7,8,9}$. The approach comprises early administration of appropriate antibiotics (ideally within 1 hour of wounding), wound debridement and wound excision before six hours, and delayed primary wound closure at
4/5 days. It is a well proven approach, having first gained acceptance following the Inter-Allied Conference of 1917. Controversy continues; the arguments have been $\Phi$ debated in the recent literature ${ }^{10,11}$.

It is noteworthy that two years after the event, both응 casualties treated by us suffer residual disability and require continuing care. The Hungerford shooting incident resulted in thirty victims; fourteen died before reaching aid, three died later in hospital yielding aO mortality for the whole group approaching $60 \%$. The mortality rate for those reaching hospital alive was over $\frac{\bar{\Phi}}{\bar{D}}$ $18 \%$. These are significant mortality rates and indicate $\stackrel{\mathbb{}}{\triangle}$ the severity of modern ballistic injury. The patho- ® physiological consequences of ballistic injury continue to be underestimated. Bellamy, in the United States, $\stackrel{\circ}{-}$ and Beverland and Rutherford in the United Kingdom $\vec{\omega}$ have recognised and reported on this phenomenon ${ }^{12,13}$. . This recognition makes an increasing trend towards@ surgical conservatism very worrying. The weight of historical evidence points to treatment failure when the orthodox approach is abandoned in favour of conservative measures ${ }^{14,15,16}$. Success in North American centres of medical excellence in treating single casualties, often with low energy-transfer

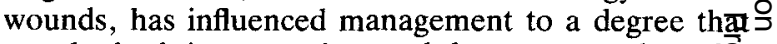
may be both inappropriate and dangerous, at least $\mathrm{fQ}_{\mathrm{r}}-$ United Kingdom practice. The majority of ballisic casualties will continue to have their initial managemest carried out by young surgeons who have little experience $\vec{\varphi}$ in the management of ballistic injury. The orthodex $\Theta$ approach offers these surgeons a well tried and proven approach and must still be recommended as the treatment of first choice for all victims of penetrati部 ballistic injury.

\section{Acknowledgements}

We would like to thank Dr G J Cooper PhD, Head of $\overrightarrow{\overrightarrow{0}}$ Trauma Section at CDE, for useful discussions on current thoughts on wound ballistic science, Gp Capt $\mathrm{M}_{F}$ Mahoney FRCS and Wng Cmdr G M Holloway FRCS for permission to report on their patients.

\section{REFERENCES}

1. BRoOME $\mathrm{G}$ et al. The Hungerford Shooting Incident. Injury $\frac{\stackrel{0}{ \pm}}{5}$ 1988; 19: 313-317.

2. BEE $\mathrm{C}$ et al. The Hungerford Multiple Shooting Incident $\frac{0}{3}$ 19th August 1987. J British Assoc Immed Care 1988; $11: 0$ 26-31.

3. KIrby $N$ G and Blackburn G. Field Surgery Pocket Book. London: HMSO, 1981: 6-13.

4. Whelan $T$ J, Burkhalter $W$ E and Gomez A. Management of War Wounds. In: Welch C E, editor. ․․․ Advances in Surgery, Vol 3. Chicago: Year Book Medical Publishers, 1968.

5. HAGELIN K W et al. Missile injury to live tissue - a method N for facilitating debridement of devitalised muscle tissue by increased colour contrast. Acta Chir Scand 1979; Suppl 489: 159-164. 
6. FACKLER M Let al. Open Wound Drainage Versus Wound Excision on the Modern Battlefield. Letterman Army Institute of Research, San Francisco: Report 256: 1988.

7. Bretler D, Sedlin E D and Mendes D G. Conservative Treatment of Low Velocity Gunshot Wounds. Clin Orthop 1979; 140: 26-31.

8. Marcus N A et al. Low-velocity Gunshot Wounds to Extremities. J Trauma 1980; 20: 1061-64.

9. FACKLER M L. What's wrong with the wound ballistics literature, and why. Letterman Army Institute of Research, San Francisco: Report 239, 1987.

10. CoOper $\mathbf{G} \mathbf{J}$ and RYAN $\mathbf{J} \mathbf{M}$. The Interaction of Penetrating Missiles With Tissues - some common misapprehensions, and the implications for wound management in peace and war. Br J Surg 1990: In Press.
11. Ryan J M, CoOper G J and MAYNard R L. Wound Ballistics: Contemporary and Future Research. JR Army Med Corps 1988; 134: 119-125.

12. Beverland D E and Rutherford W H. An Assessment of the Validity of the Injury Severity Score when applied to Gunshot Wounds. Injury 1983; 15: 19-22.

13. Bellamy R F and Vayer J S. Assessment of Penetrating Injury Severity. In: Maull K I, editor-in-chief. Advances in Trauma, Vol 1. Chicago: Year Book Medical Publishers, 1988: 1-20.

14. Odling-Smee $G$ W. Ibo Civilian Casualties in the Nigerian Civil War. Br Med J 1970; 2: 592-596.

15. Dudley H A F et al. Civilian Battle Casualties in South Vietnam. Br J Surg 1968; 55: 332-340.

16. OGILVIE $H$. Lessons of the war that are already being forgotten. Guy's Hosp Gazette 1956; October Vol: 401-405. 